RESEARCH REPORT

\title{
ASSESSMENT OF HAMSTRING FLEXIBILITY RETENTION THROUGH SIT-AND-REACH BOX IN UNIVERSITY STUDENTS WITH NON- SPECIFIC LOW BACK PAIN
}

\begin{abstract}
OBJECTIVES

Administrationof sit and reach (SR) box as an intervention tool for retaining the hamstring flexibility as a treatment regime in order to prevent as well predict future low back pain complications. Improvement of hamstring flexibility through SR box, administrationof SR box as an assessment tool in patients with reduced hamstring flexibility causing low back pain complications. Also implementation of SR box for training purpose in clinical practice to evaluate the efficacy of the SR box in retention of hamstring flexibility in both genders.

STUDY DESIGN

A quantitative experimental study inclusive of simple random sampling was done. The independent variables were age and gender. Flexibility retention and treatment were the dependent variables which were assessed by a Sit-and-reach box.

\section{MEASUREMENTS}

The subject pool for this study consisted of 40 volunteers that were selected on the basis of simple random sampling and were recruited in the study after assessing hamstring tightness through toe-touching, straight leg raise and piriformis test to exclude any specific pathology or disorders.

RESULTS

Flexibility showed marked increase in most of the applicants on 5th trial after a 4 week training regime by sit and reach box.

\section{CONCLUSION}

Achievements in flexibility are preserved for no less than 2 weeks after a stretching program. It additionally created the impression that 2 sets; each consisting of 3 repetitions of a sit-and-reach test is adequate for boosting extensive increment in flexibility.
\end{abstract}

\section{KEYWORDS}

Sit-And-Reach, Stretching, Flexibility, Hamstring, Low Back Pain, Straight Leg Raise.

\section{Sumaira Imran Farooqui}

Associate Professor, Principal Ziauddin College of Physical Therapy Ziauddin University sumairaimranfarooqui@gmail.com

\section{Zulekha Saleem}

DPT, Student

Ziauddin College of Physical therapy

Ziauddin hospital zulekha_saleem@hotmail.com

\section{Ashbeel John Edgar}

DPT, Student

Ziauddin College of Physical therapy

Ziauddin Hospital

dr.ashbeel89@gmail.com

\section{Shahida Abbass}

DPT, Student

Ziauddin College of Physical therapy

Ziauddin Hospital

shahidaabbas97@yahoo.com

[Farooqui SI, Saleem Z, Edgar AJ, Abbass S. Assessment of hamstring flexibility retention through sit-and-reach box in University students with non-specific low back pain.2016;5(1):31-38] 


\section{INTRODUCTION}

Flexibility is foreseen as a vital element of physical wellbeing'. Generally, a prior history of Low Back Pain (LBP) often times anticipated the tendency of potential back issues ${ }^{2}$. Non Specific Low Back Pain (NSLBP) is defined as muscle firmness underneath the costal edge and superior to the inferior gluteal folds, with or without sciatica or piriformis syndrome ${ }^{3}$. So, accordingly it is a pain not accredited to an identifiable pathology such as an infection, osteoporosis, rheumatoid arthritis, tumor, bone fractures or inflammation ${ }^{3}$. However, it is elucidated as chronic when it continues for 12 weeks or great$\mathrm{er}^{3}$. As specified by WHO, acute LBP is the most well-known exhibiting dissention and is generally self-resolving, not exceeding three months regardless of treatment ${ }^{4}$.

The statistical data points express that, non-specific LBP is considered as a real part of the general wellbeing issues, and the incidence of LBP over the lifetime is as high as $84 \%$, whereas, the recurrence of chronic LBP is around $23 \%$, with $11-12 \%$ of the population are at the risk of being disabled by LBP5 . In addition to the above data; LBP occurs as a periodic event in grown-ups with relatively $60-80 \%$ of the general population experiencing LBP once in an existent time ${ }^{2}$. Perhaps, prevention of LBP in early stage of adulthood may eventually contribute to forestalling and decreased risk of having back pain in the said stage of life ${ }^{2}$.Subsequently, the exact etiological component of LBP stays idiopathic ${ }^{2}$. Conceivable danger elements associated with LBP incorporate constitutional variables comprising of age, gender, muscular strength, postural-structural, smoking, occupational, recreational and psychosocial, for example, anxiety and depression attributes $^{2}$. A fact has been highlighted in the literature that, greater strength of abdominal muscles and Its endurance, enhanced low back and hamstring flexibility, or both may provide defense against emergence of $\mathrm{LBP}^{2}$. The most extensively used fitness and strength tests in young and adult individuals i.e. The Prudential FITNESSGRAM', President's Challenge ${ }^{7}$, or AAU Fitness Program ${ }^{8}$ include measures of abdominal strength, lower back and hamstring flexibility².

Additionally, a research likewise also focuses on the risk factors for LBP which have been postulated as diminished muscle flexibility and trunk strength ${ }^{9-11}$, which has been highlighted in this study. However, cross-sectional studies in adolescence as well as adults have shown association of poor hamstring flexibility with low back pain ${ }^{11-13}$, while another study in a group of labors has not affirmed the conclu$\operatorname{sion}^{14}$.

Thus, as described that taut hamstring leads to hamstring strains and lower-back pain; it might likewise intervene with healthy posture, by bringing on the pelvis to tilt back. As the hamstringsand lumbar extensor musculature start from the pelvis, there might be likely relationship amongst these structures ${ }^{15}$. Accordingly, laxity of one structure maycorrespondingly influences the quality and position of the other to hold pelvis control, which may add to the LBP evolution ${ }^{15}$. Hence, it might be that diminished flexibility in the hamstrings is a consequence of non-specific LBP potentially due to the lack of activity relatively than a known cause ${ }^{16}$.

Considering hamstring flexibility; diverse evaluation strategies are utilized; including sit and reach (SR) test, Modified SR test, Back saver SR test (BSSR), toe-touch tests and Modified V-SR test. The SR test was at first portrayed by Wells and Dillon in 1952 to present effective measurement criteria of hamstring and lower back flexibility?.

The SR test is used as a practically applicable and workable test to evaluate low back and hamstring muscle strength. Because of its effectiveness; most health related fitness test batteries consist of this test. It is believed that maintenance of hamstring and low back flexibility may prevent injuries of the musculoskeletal system, including low back problems, gait limitations and postural deviations ${ }^{17}$.

SR tests are reportedly included on the grounds that abdominal strength or endurance and low back-posterior thigh flexibility is vital for the prevention and rehabilitation of low back disorders ${ }^{18}$. Reliability estimates from the previous studies for the standard SR test are consistently high i.e. $0.96<0.99$ 18,20,21. Conversely, a study conducted by Jackson et al 22 in 1998 have recommended that the SR test is inconsequential to LBP status, and they interrogate its incorporation in testing protocols for the measurement of low back flexibility. Consecutively, in 1998 a study by Jackson et al ${ }^{22}$ with a genuinely gigantic sample size of about 2,747 subjects remained unsuccessful in discovering a relationship either linear or otherwise, between SR scores and LBP incidence.According to Jackson et al. in 1998; Minkler and Patterson, in 1994; S\&R scores are anticipated to represent low back flexibility and have been used as an alternate indicator of low back health (Albert et al., 2001; Gledhill, 2001)22. Hui and Yuen's report in 2000 edifies the fact that the SR test is authentic and consistent as compared to other modified versions of the test ${ }^{22}$. Substantially, SR tests have a moderate mean criterion-related validity for estimating hamstring extensibility, while they have a low mean validity for assessing lumbar extensibility which has been the essential point of our study ${ }^{23}$ The results of the research led by G Baltaci et al ${ }^{17}$ indicated that the SR and BSSR tests have intrinsic and constitutional limitations for adults having low back disorders or having difficulty sitting on a plain uniform surface with the knees extended. Therefore, they proposed Chair sit-and-reach test as a surrogate tool for assessing hamstring flexibility in elderly 
individuals ${ }^{17}$.

In spite of the fact that, SR tests are moderately valid measures of hamstring flexibility but do not adequately quantify lumbar flexibility, still they are the solitary field tests that are followed practically and are simply administered. Additionally, the principle center of this study is to address that the reliability of SR tests is quite high, a solitary estimation seems to be sufficient to ensure accuracy when warm up stretching and practice are allowed ${ }^{17}$.

An integral part of sports and physical assessment is testing the flexibility of hamstring musculature. SR test has been broadly utilized as a marker of hamstring elasticity since years. Even though, it stays conflicting if the test adequately measures the lower back flexibility andexclusively very few researches has been conducted in which the sit and reach box is used as an intervention tool for the retention of hamstring flexibility. As per investigation, the validity of the SR test, declaring that a person is likely to accomplish the task effortlessly if he has a flexible trunk, short arms and extensible legs achieves the task easily. However, a present-day study does not confirm this claim. The standard system (SR test) is restricted to a solitary measure and does not have a convention that permits to determine passive range of motion, however its mechanics and methodology reveals that it can be recognized as a treatment administration of enhancing hamstring elasticity.Remembering such claims, our study is critical to discover the legitimacy of the SR box in evaluating both; hamstring and low back adaptability and also enhancing its adaptability measures and retaining it. The study is basic for anticipating the likelihood of creating future back issues as well and can help in the maintenance of the hamstring adaptability.

\section{METHODOLOGY}

\section{Research Design and Methods}

Quantitative research strategy was followed and the research design is experimental. The data was collected through simple random sampling.

\section{Population and Study Sample}

The applicant group for this study entailed 40 college going students. The candidates belonging from both genders and young university students were selected for the study who has not presented any history of injury, physical/ mental disability or musculoskeletal injury, fulfilling the inclusion criteria after a detailed assessment. The volunteers were enrolled in the study after the agreement to the informed consent form.

\section{Sample Size and Selection of Sample}

The study comprised of 40 volunteers that were chosen on the premise of simple random sampling and were recruited in the study after evaluating hamstring tightness through toe-touching, straight leg raise and piriformis test to exclude any specific pathology or disorder.

\section{Inclusion Criteria}

1. Participants representing without any history of injury, physical or mental disability.

2. Subjects with mean age of $20-40$ years.

3. Participants with no pathological musculoskeletal constraints.

4. The subjects without specific Low back pain experience.

\section{Exclusion Criteria}

1. Subjects with a history of any recent surgeries in low back and lower limbs.

2. Recent musculoskeletal injuries including joint dislocation or instability and soft tissue injuries.

3. Participants having neurological impairment.

4. Participants with any deformity or disability seeking medical attention.

\section{Collection of Data}

The data was selected on the basis of simple random sampling. The participants included in the study were those who satisfied the inclusion criteria after being evaluated by a questionnaire, an assessment form and special testing procedures such as straight leg raise, toe-touching and piriformis test.

Forty university students both males and females were examined for tightness of hamstrings. The participants were encouraged to have a brief session consisting of a brisk walk lasting for only 3 minutes. An extensive warm-up was performed by every participant before pre-test which included active hamstring stretches for 30 seconds, 3 repetitions on each leg. The instructor guided the subject to refrain from jerky or trick movements.

During testing, subjects sat barefoot with their legs under the edge of the sit-and-reach box, both legs were extended, heel against the surface. In an effort to reduce triceps surae muscle tightness, the ankle was plantar flexed over the 2-in-diameter so that the toes touched the sit-and-reach box. Subjects then overlapped their hands and slowly stretched forward as far as the right leg could allow. The distance that subjects' fingers reached along the sit-and-reach box was recorded; the best of 3 trials was used for statistical analysis.

\section{Figure 1}

Sit and reach box

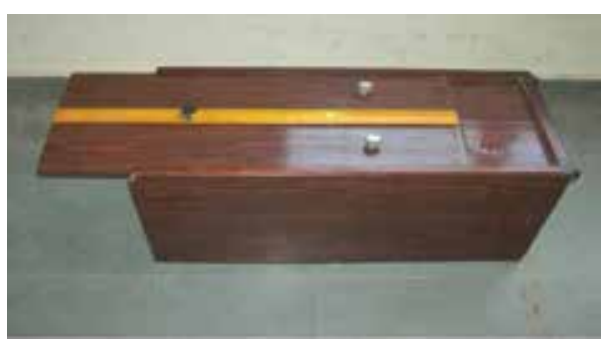


Figure 2 The participant in starting position of sit and reach test box.

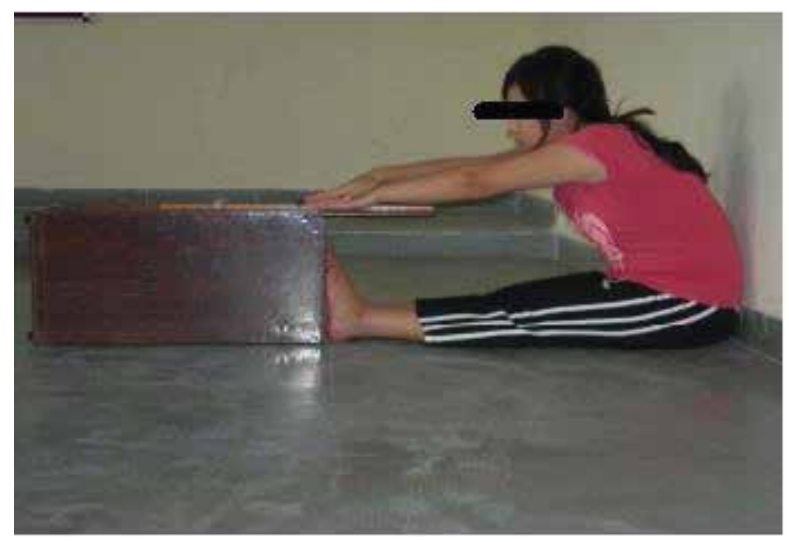

Figure 2.1

The participant is in stretched position of sit and reach test box.

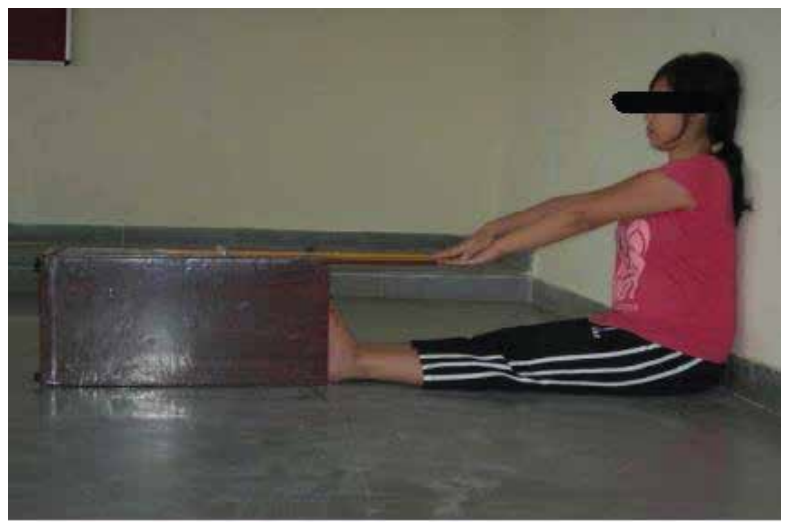

The participants were graded according to the score table given below.

SCORE TABLE ${ }^{[32]}$

\begin{tabular}{|l|c|c|c|c|}
\hline \multicolumn{1}{|c|}{ GRADES } & Women (cm) & Women (inches) & MEN(cm) & Men(inches) \\
\hline Excellent & $<24$ & $24-29$ & $30-33$ & $34-37$ \\
\hline Very Good & $<19$ & $19-23$ & $24-27$ & $28-31$ \\
\hline Good & $<12$ & $13-17$ & $19-22$ & $23-27$ \\
\hline Average & $<9$ & $9-13$ & $15-18$ & $19-22$ \\
\hline Poor & $<7$ & $7-11$ & $12-14$ & $17-20$ \\
\hline
\end{tabular}

\section{Data Management}

The research data was prepared for analysis by using numerical codes for categorical variables and labeled them to avoid perplexity. The data was stored in the database and proper back-ups were made. During the data collection; strict rules and regulations were followed regarding data preservation and confidentiality of the participant's information was assured.

A log book has also been formed for data management which contains the record for later use. The log book has particular information about the title of the thesis project, list of authors, and proper documentation of the volunteer's information, research questionnaire, assessment forms, statistical data analysis methods and outcomes of the research.

\section{Data Analysis Strategies}

The participants were divided into four groups. The categorization of the tables was on the basis of male and female. Further the groups were named as A, B, C and D. Frequency analysis was performed for all categorical variables. The data was collected through sit and reach box. Once the data was recorded and measured in centimeter then Microsoft excel program was used to combine the data and SPSS (version 2.0) was used to apply the t-test on the data in order to show the difference among groups.

\section{DISCUSSION}

The sole purpose of the study was to identify the maintenance of flexibility of the hamstring muscle through implementing SR box in college undergradvates who expressed the symptoms of non-specific low back pain. The result varied over the time frame of the training regime which was implicated for two consecutive weeks for five alternate days. Drastically the results showed significant difference in increment of the flexibility on the first trial which continved to increase till the fifth trial in most of the applicants as discussed in the results. However, few participants were assessed as very poor with a score of zero in their pre-test initial assessment and their increment was slower than others on $2^{\text {nd }}$ and $3^{\text {rd }}$ trials, although their flexibility was retained on the fifth trial. Since the participants of our study were the students of who had a sound medical knowledge regarding the main elements of the study that is the stretching of hamstring. Due to this, theprocedure and information of the study was easily communicated.

Although main results showed comprehensive improvement in hamstring flexibility on $1^{\text {st }}, 2^{\text {nd }} 3^{\text {rd }}, 4^{\text {th }}$ and $5^{\text {th }}$ trial and at the end of the treatment for 2 weeks after five trials of stretching by means of sit and reach box in both male and female participants. Very less significant difference was observed between the results of both genders. Male participants showed greater improvement as compared to female participants. As the study consisted of only 40 participants (Male=17 and Female=23) which were university students, however a major variation between hamstring flexibility could be noted in both the genders if a considerably huge data is allotted. Nevertheless, the main purpose of this study was not how the flexibility was improved but how it can be retained.

SR box is eminent to be applied as a gold standard treatment tool for evaluating the elasticity of ham- 
string muscle since decades ${ }^{24}$. The main emphasis of conducting this type of study was to introduce the sit and reach box in clinical practice as an intervention as well as a diagnostic tool, so that it can be described as a tool that assesses hamstring flexibility and also assists in improving and retaining the flexibility. There are very few researches conducted to support the objectives of this study. Further researches are needed to be carried out to prove that the sit and reach box is useful as a treatment option in individuals with NSLBP.

The subject's flexibility changes were similar to other studies as well ${ }^{25,26}$. According to Rubleyet $\mathrm{a}^{25}$. The flexibility of hamstring increased with time from day one to fifth day about $19-21 \%$ with $26-23 \%$ between day one and eight and $20 \pm 20 \%$ between day one to thirtieth. The study finally concluded that there was no difference between days 5,8 , and 30 .

Sullivan et $\mathrm{al}^{26}$ suggested that there was $18 \%$ enhancement in range of motion after undergoing a standing staticstretching of hamstring just one time on a daily basis and continued for four times per week. Conceivably one week of stretching is as compelling as six weeks of stretching.

Halbertsma et al ${ }^{27-29}$ reported that the improvement in range of motion subsequent to stretching is a consequence of an increment in stretch tolerance, which the subjects term as pain tolerance as opposed to extensibility or inflexibility of the hamstring muscle.
Our study did not include the measurements of muscle lengthening or stiffness, so our subjects' flexibility increment cannot be suggested. However, it appears that the increment in flexibility was a consequence of concise SR box tests which may be a reason for addition by subjects' stretch tolerance. There is a speculative relationship between measures of musculoskeletal quality, elasticity, adaptability and LBP ${ }^{30}$. However, the essential support for the SR test is clinical in nature i.e. people with LBP have confined range of movement in the hamstrings and low back ${ }^{31}$.

This data promptly raises many questions such as to what extent does the retention last? Is there any relationship between the length of treatment period and the period of retention? Does the retention expand, decline or plateau if we increase the intensity, duration and frequency of the treatment? Can we utilize these protocols in the treatment of various sports related musculoskeletal disorders? is the sit and reach box training regime supportive in alleviating low back pain.

Further studies should likewise be possible in future in athletes, who are at high risk for hamstring injuries and need to improve their hamstring flexibility with the goal that they can rapidly return to sports activities. Effectiveness of sit and reach box training regime between male and female patients to enhance the hamstring flexibility can furthermore be performed.

\begin{tabular}{|c|c|c|c|c|c|c|c|c|c|}
\hline \multicolumn{10}{|c|}{ Paired Samples Test } \\
\hline & & \multicolumn{5}{|c|}{ Paired Differences } & \multirow[b]{2}{*}{$t$} & \multirow[b]{2}{*}{ df } & \multirow[b]{2}{*}{ Sig.(2-tailed } \\
\hline & & Mean & Std.Deviation & $\begin{array}{l}\text { Std.Error } \\
\text { Mean }\end{array}$ & Lower & Upper & & & \\
\hline Pair 1 & $\begin{array}{l}\text { Pretest score - post test } \\
\text { score } 1\end{array}$ & -1.84250 & 2.00050 & .31631 & -2.48229 & -1.20271 & -5.825 & -39 & .000 \\
\hline Pair 2 & $\begin{array}{l}\text { Pretest score - post test } \\
\text { score } 2\end{array}$ & -3.60750 & 2.45956 & .38889 & -4.39411 & -2.82089 & -9.276 & -39 & .000 \\
\hline Pair 3 & $\begin{array}{l}\text { Pretest score - post test } \\
\text { score } 3\end{array}$ & -5.35500 & 3.02651 & .47853 & -6.33293 & -4.39707 & -11.211 & -39 & .000 \\
\hline Pair 4 & $\begin{array}{l}\text { Pretest score - post test } \\
\text { score } 4\end{array}$ & -6.76750 & 3.29688 & .52128 & -7.82189 & -5.71311 & -12.982 & -39 & .000 \\
\hline Pair 5 & $\begin{array}{l}\text { Pretest score - post test } \\
\text { score } 5\end{array}$ & -8.19000 & 3.61129 & .57100 & -9.34495 & -7.03505 & -14.343 & -39 & .000 \\
\hline
\end{tabular}




\section{RESULTS}

Forty individual university students both Male $(\mathrm{N}=17)$ and female ( $\mathrm{N}=23$ ) with age group from 18 - 28 years were selected for the study.

Table 1 shows statistical difference in pretest and post test score after five trials $(p=0.000)$

\section{TABLE-1}

\begin{tabular}{|r|c|c|c|c|c|c|}
\hline & & Mean & Mean & Mean & Mean & Mean \\
\cline { 2 - 6 } & $\begin{array}{c}\text { Pretest } \\
\text { score }\end{array}$ & $\begin{array}{c}\text { Post test } \\
\text { scorel }\end{array}$ & $\begin{array}{c}\text { Post test } \\
\text { score2 }\end{array}$ & $\begin{array}{c}\text { Post test } \\
\text { score3 }\end{array}$ & $\begin{array}{c}\text { Post test } \\
\text { score4 }\end{array}$ & $\begin{array}{c}\text { Post test } \\
\text { score5 }\end{array}$ \\
\hline $\begin{array}{r}\text { Sender male } \\
\text { female }\end{array}$ & 10.62 & 13.09 & 14.94 & 16.74 & 18.51 & 20.09 \\
12.96 & 14.67 & 16.40 & 17.53 & 18.83 \\
\hline
\end{tabular}

The above table-1 shows that the comparison of pretest score with post test score 1, 2, 3, 4 and 5 respectively. Paired sample test shows that there is significant improvement in flexibility of hamstring muscle after every trail as compare to pretest hamstring muscle flexibility in both male and female participants by means of sit and reach test box.

\section{TABLE-2}

\begin{tabular}{|c|c|c|c|c|}
\hline \multicolumn{5}{|c|}{ Paired Samples Statistics } \\
\hline & Mean & $\mathrm{N}$ & $\begin{array}{c}\text { Std. } \\
\text { Deviation }\end{array}$ & $\begin{array}{c}\text { Std. } \\
\text { Error Mean }\end{array}$ \\
\hline pretest score & 11.1750 & 40 & 4.23894 & .67023 \\
\hline post test score 1 & 13.0175 & 40 & 4.81812 & .76181 \\
\hline pretest score & 11.1750 & 40 & 4.23894 & .67023 \\
\hline Pair 2 post test score2 & 14.7825 & 40 & 4.67179 & .73867 \\
\hline pretest score & 11.1750 & 40 & 4.23894 & .67023 \\
\hline 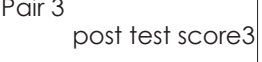 & 16.5400 & 40 & 4.70405 & .74378 \\
\hline pretest score & 11.1750 & 40 & 4.23894 & .67023 \\
\hline Pair 4 post test score 4 & 17.9425 & 40 & 4.64299 & .73412 \\
\hline Pair 5 pretest score & 11.1750 & 40 & 4.23894 & .67023 \\
\hline post test score 5 & 19.3650 & 40 & 4.29111 & .67848 \\
\hline
\end{tabular}

Table-2 indicates that the mean value of pretest score that is 11.1750 which increased in post test score 1 that is 13.0175 and there was significant increase after five trials that is mean value of post test score 5 that is 19.3650 which correlates that the flexibility started improving from the post test score 1 until post test score 5 .

\section{TABLE-3}

\begin{tabular}{|ll|c|c|c|}
\hline \multicolumn{1}{|c|}{ Paired Samples Corrections } \\
\hline & & N & Correction & Sig. \\
\hline Pairl & pretest score \& posttest score 1 & 40 & .910 & .000 \\
Pair2 & pretest score \& posttest score 2 & 40 & .852 & .000 \\
Pair3 & pretest score \& posttest score 3 & 40 & .776 & .000 \\
Pair4 & pretest score \& posttest score 4 & 40 & .728 & .000 \\
Pair5 & pretest score \& posttest score 5 & 40 & .642 & .000 \\
\hline
\end{tabular}

Table-3 indicates the level of significance when the pretest was compared with all 5 post test scores.

\section{FIGURE-3}

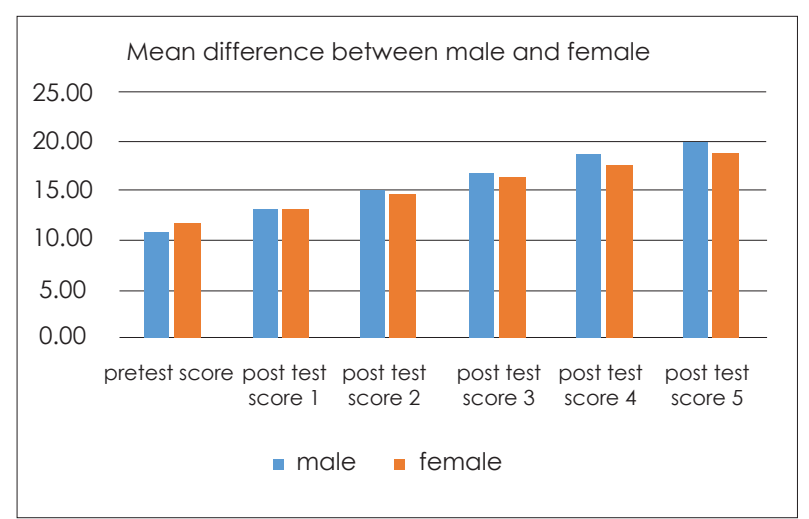

Figure 3 shows graphical representation of the comparison of the increase in flexibilty in pretest score and all 5 post test score in both male and female participants.

\section{Limitations of the study}

1. The flexibility measurement score was affected due to the sense of competitiveness observed among the participants.

2. Individuals having long arm and legs easily accomplish the task; making the result unreliable when comparing participant's scores.

3. The difference in scores was observed according to the participant's dressing. It was observed that 
participants when worn loose-fitted clothing and performed the test; secured a higher score and when the similar participant worn close-fitting clothing; could rarely go beyond the previously achieved score.

4. Since the study was not conducted in a health care set up, influence of individual's occupation on hamstring flexibility could not be evaluated.

\section{CONCLUSION}

The outcome of the research concludes that hamstring stretching through sit-and-reach box with a thorough warm up lasting for 1 minute performed lead to improved hamstring flexibility. This research clearly shows that hamstring training for alternate 5 days consisting of 30 seconds brisk walk and 3 static hamstring stretches as warm up and further 3 hamstring stretches on sit-and-reach box leads to enhanced flexibility of the particular muscle. It shows that the flexibility scores improved gradually day-to-day and the results were more considerable in males as compared to females. The flexibility score was highest on the final i.e. the fifth day of assessment which proves that 1 minute of extensive warm up (brisk walk and static stretches) and 3 sit-and-reach stretches were adequate to attain greater flexibility.

\section{REFERENCES}

[1] Lemmink K, Kemper $H$, Greef $M$, Rispens $P$, Stevens $M$. The validity of the sit-and-reach test and the modified sit-and-reach test in middle-aged to older men and women. Res Quart Exer Sport. 2003;74(3):331-336

[2] Jackson A, Morrow J, Brill P, Kohl H, Gordon N, Blair S. Relations of sit-up and sit-and-reach tests to low back pain in adults. J Orthop Sports Phys Ther. 1998;27(1):22-26

[3] Chou R. Low back pain (chronic). Clin Evid Handbook. Health \& Science University, Portland, Oregon 201 1:84:403-405

[4] Ehrlich GE, Ehrlich GE, Khaltaev NG. Low back pain initiative. Geneva: WHO;1999.

[5] Balagué F, Mannion AF, Pellisé F, Cedraschi C. Non-specific low back pain. Lancet. 2012;379(9814):482-491

[6] Cooper Institute for Aerobics Research. The prudential fitnessgram. Dallas: The Cooper Institute for Aerobics Research; 1992

[7] The President's Council on Physical Fitness and Sports. President's Challenge. WashingtonDC: The President's Council on Physical Fitness and Sports; 1994.

[8] Amateur Athletic Union. Amateur Athletic Union Physical Fitness Program. Indianapolis: AAU National Headquarters; 1994.

[9] Schmidt-Olsen S, Jorgensen $U$, Kaalund $S$, Sorensen J. Injuries among young soccer players. Am J Sports Med. 1991;19(3):273-275

[10] Kujala UM, Salminen JJ, Taimela S, Oksanen A,
Jaakkola L. Subject characteristics and low back pain in young athletes and nonathletes. Med Sci Sports Exer. 1992;24(6):627-632

[11] Kujala UM, Taimela S, Oksanen A, Salminen JJ. Lumbar mobility and low back pain during adolescence: a longitudinal three-year follow-up study in athletes and controls. Am J Sports Med. 1997;25(3):363-368

[12] Salminen J, Maki P, Oksanen A, Pentti J. Spinal mobility and trunk muscle strength in 15-year-old schoolchildren with and without low-back pain. Spine. 1992;17(4):405-411

[13] Hultman G, Saraste H, Ohlsen H. Anthropometry, spinal canal width and flexibility of the spine and hamstring muscles in 45-55- year-old men with and without low back pain. J Spinal Disord. 1992;5(3):245-253

[14] Battié, M Bigos S, Fisher L, Spengler D, Hanssont, Nachemsona et al. The role of spinal flexibility in back pain complaints within industry: a prospective study. Spine. 1990;15:768-773

[15] Mistry G, Vyas N, Sheth M. Comparison of hamstrings flexibility in subjects with chronic low back pain versus normal individuals. J Clin Experi Res. 2014;2(1):85

[16] Feldman DE. Risk factors for the development of low back pain in adolescence. Am J Epidemiol. 2001;154(1):30-36

[17] Baltaci G. Comparison of three different sit and reach tests for measurement of hamstring flexibility in female university students. Bri J Sports Medi. 2003;37(1):59-61

[18] Jackson AS. The evolution and validity of health-related fitness. Quest: Informa UK. 2006;58(1):160-175

[19] Jackson AW, Baker AA. The relationship of the sit and reach test to criterion measures of hamstring and back flexibility in young females. Res Quart Exer Sport. Informa UK. 1986;57(3):183-186

[20] Jackson A, Langford NJ. The criterion-related validity of the sit and reach test: replication and extension of previous findings. Res Quart Exer and Sport. Informa UK. 1989;60(4):384-387.

[21] Luhring A, Rivera-Brown A, Frontera WR. Reliability of the aahperd functional fitness assessment battery in older adults 972. Med Sci Sports Exer. 1996;28(Suppl):163

[22] Grenier SG, Russell C, Mcgill SM. Relationships between lumbar flexibility, sit-and-reach test, and a previous history of low back discomfort in industrial workers. Canad J App Physiol. 2003 ;28(2):165-177

[23] Mayorga-Vega D, Viciana J, Cocca A, Merino-Marban R. Criterion-related validity of toe-touch test for estimating hamstring extensibility: a meta-analysis. J Hum Sport Exer. 2014:9(1):188-200

[24] Moral-Muñoz JA, Esteban-Moreno B, Arroyo-Morales M, Cobo MJ, Herrera-Viedma E. Agreement between face-to-face and free software video analysis for assessing hamstring flexibility in adolescents. J Streng Condition Res. 
2015;29(9):2661-2665

[25] Rubley MD, Brucker JB, Knight KL, Ricard MD, Draper DO. Flexibility retention 3 weeks after a 5-day training regime. J Sport Rehabil. 2001;10:105-112

[26] Sullivan MK, Dejulia JJ, Worrell TW. Effect of pelvic position and stretching method on hamstring muscle flexibility. Med Sci Sports Exer. 1992;24(12):1383-1389

[27] Halbertsma JPK, van Bolhuis Al, Göeken LNH. Sport stretching: effect on passive muscle stiffness of short hamstrings. Arch Phys Med Rehabil. 1996;77(7):688-692
[28] Halbertsma JP, Goeken LN. Stretching exercises: effect on passive extensibility and stiffness in short hamstrings of healthy subjects. Arch Phys Med Rehabil. 1994;75:976-981.

[29] Halbertsma JPK, Mulder I, Göeken LNH, Eisma WH. Repeated passive stretching: acute effect on the passive muscle moment and extensibility of short hamstrings. Arch Phys Med Rehabil. $1999 ; 80(4): 407-414$

[30] Plowman SA. Physical activity, physical fitness, and low back pain. In: Holloszy. 10thed. Exercise and Sport Sciences Reviews, pp 22 1-242. Baltimore, MD: Williams \&Wilkins, 1992. 